\title{
Adverse selection, volume and transactions around dividend announcements in a continuous auction system
}

\author{
Gonzalo Rubio and Mikel Tapia
}

Departamento de Fundamentos, Facultad de Ciencias Económicas, Universidad del País Vasco, Avda L. Aguirre 83, 48015 Bilbao, Spain

\begin{abstract}
We show that liquidity providers do not significantly respond to changes in information asymmetry risks, at least when we analyse their trading behaviour around dividend announcements of a representative sample of stocks in a continuous auction trading mechanism. The implicit bid-ask spread does not seem to change beyond what is normally conveyed through an increased number of transactions. We also document that the information in the trading behaviour of investors is primarily contained in the number of daily transactions.
\end{abstract}

Keywords: adverse selection, bid-ask spread, limit orders, dividend announcements.

JEL classification: $G 14$.

\section{Introduction}

Trading mechanisms for equities present alternative characteristics around the world. In general, trading systems can be classified into batch markets and continuous markets. In this paper, we are concerned with a continuous market where a transaction takes place whenever two orders are matched. It is well known that this mechanism provides continuous price information throughout the period in which the market is open. Moreover, continuous markets are either dealer markets or auction markets. Of course, in a dealer market, the trading mechanism is driven by prices with exchange-designated specialists providing liquidity to the market. Ask and bid prices and the number of shares available at each quote are offered simultaneously by market makers. It is also the case that specialists are obliged to maintain a limit order book containing the public's limit orders. On the other hand, in the auction system, public trading orders are directly matched against one another. These are markets driven by orders. In 1989, the Spanish Stock Exchange became a continuous auction system by 
adopting the computer assisted trading system (CATS). 'The public's limit orders are displayed in a computer file. In this way, execution against limit orders left on the computerised book is allowed by the trading mechanism. By monitoring available bids and offers on the book, stock exchange agencies (brokers) can execute upcoming orders against an existing bid or offer. Alternatively, they can introduce a new sale or purchase order. Thus, public limit orders represent the available bids and offers. In this sense, the analogue of the bid-ask spread on the continuous auction system is the spread between the best buy and sell limit orders outstanding at any given time. Even without a market maker who continuously establishes quotes, it is the case that when an investor tries to sell any amount of stock, he or she gets a lower price than the price that has to be paid for it. In a continuous auction market, agents or speculators trying to absorb temporary imbalances of supply and demand to make a profit will require a premium from buyers and impose an additional compensation on sellers.

It is important to realise that in setting the implicit bid-ask spread, we run into the same reasons that induce market makers to be compensated. In particular, they need to be remunerated for taking risky positions, for the risk of trading with an insider, and for the expenses necessary to maintain their presence in the market. In a mechanism driven by prices, dealers set the spread to protect themselves from trading with better informed individuals. Dealers expect to lose on average to better informed traders and gain on average from transactions with uninformed traders. The same reasoning applies to continuous auction markets throughout the establishment of public limit orders.

The objective of this paper is to study the importance of the asymmetric information component of the implicit bid-ask spread in a continuous auction market. If, given asymmetric information among traders, the adverse selection component is present, the implicit spread should be higher (lower) whenever the probability of information differential among traders has augmented (diminished).

Surprisingly, empirical adverse selection literature is exclusively concentrated on trading mechanisms where the market maker plays an explicit role. Recently, Lehmann and Modest (1994) carefully describe the trading and liquidity characteristics of the Tokyo Stock Exchange. However, they do not analyse the potential adverse selection component within the difference between the best buy and sell limit orders outstanding.

In order to study the importance of adverse selection on the implicit bid-ask spread, we analyse the effects of information announcements on the spread. Given that signalling theories suggest that dividends convey information about managers' expectations regarding the future cash flows of the firm, the spread should be expected to change during periods of dividend announcements. Moreover, the analysis can be easily extended to the study of market liquidity by considering the effects on depths. It should be recalled that liquidity effects are unambiguous only when we observe a spread increase (decrease) and a simultaneous depth decrease (increase). ${ }^{2}$

When we conduct univariate tests on the impact of the arrival of new information regarding dividends on spread and depth, our empirical evidence seems to support important adverse selection effects on spread. ${ }^{3}$ However, there exists a significant inverse relation between either volume or the number of transactions and spread. Moreover, this inverse relation is shown to be dominated by the 
number of transactions. This is an interesting result. It should be noted that Jones et al. (1994) argue that it is the occurrence of transactions, and not their size, that is behind volatility. Our results tend to support this evidence even in continuous auction markets. In fact, when we relate volatility to average trade size and to the number of transactions, the results suggest rather unambiguously that there exists only a positive relation between volatility and the number of transactions.

Once this inverse relation is incorporated into the analysis of the effects of dividend announcements on the spread, we are not able to find any compensation for adverse selection in the reaction of spread. This result remains the same whether we observe increased, maintained or decreased dividends over the previous payment. Thus, we may argue that investors are not significantly compensated for adverse selection, at least when we infer our conclusions on the basis of limit orders data around dividend announcements. Liquidity providers in continuous auction trading mechanisms do not seem to be sensitive to changes in information asymmetry risks.

The paper is organised as follows. Section 2 describes our data. In Section 3, we present an analysis of the seasonal characteristics of trading and liquidity on the continuous Spanish Stock Exchange market. Univariate tests regarding dividend announcements and liquidity are reported in Section 4. The relation, in a time-series framework, between spreads, volume and transactions is presented in Section 5, and a similar analysis related to volatility is contained in Section 6 . Our multivariate empirical evidence about the effects of dividend announcements on the implicit bid-ask spread is reported in Section 7. Finally, we summarise our results and provide some conclusions in Section 8.

\section{Data}

The data employed in this paper are obtained from two data sources. The first set consists of daily closing transaction prices for 100 companies traded on the continuous Spanish market from 19 April 1990 to 18 October 1994. ${ }^{4}$ Continuously compounded daily returns adjusted for dividends and changes of capital structure are calculated for each stock in the sample. The returns on all stocks available during each day are used to compute an estimate of the daily return on the equally weighted market portfolio. At the same time, this data set contains the total number of shares traded in each stock during each day of the sampling period. Finally, we have the number of shares outstanding for each stock at the end of each year from 1989 to 1993.

The second data set consists of the average of the five best daily prices available for both purchases (the ask) and sales (the bid) for 70 stocks from 2 January 1991 to 18 October $1994 .^{5}$ As we have already pointed out, under the adverse selection argument, if the probability that some traders have insider information has increased, liquidity providers may react by either increasing the bid-ask spread or by diminishing the number of shares available at each side of the market (depth). Fortunately, our data contain the number of shares available at each price, again as the average of the five best selling and buying positions in the market. Finally, this data set includes the number of transactions for each of the 70 stocks during each day of the sampling period. Several filters are run on the data in order to eliminate potential data errors. 
All of this information is employed to calculate the following four liquidity characteristics for each of the 70 stocks:

1. Spread $=$ Ask - Bid.

2. Relative Spread $=\frac{\text { Ask }- \text { Bid }}{(\text { Ask }+ \text { Bid }) / 2}$.

3. Depth $=$ Depth at Ask + Depth at Bid.

4. Turnover $=\frac{\text { Number of shares traded per day }}{\text { Number of shares outstanding at the end of the previous year }}$

The 70 stocks with complete liquidity and return data are ranked according to their market value at the end of the year preceding the daily return calculation. This ranking is maintained throughout each year from 1991 to 1994, and five equally weighted portfolios with approximately the same number of stocks are obtained. Portfolio one contains the smallest firms and portfolio five the largest.

In the Spanish market, priority for crossing a transaction is determined by price. If prices turn out to be equal, then priority is given to the arrival time of the order. Moreover, during the sample period of the study, the lot market is the most representative way of trading in the Spanish continuous auction system. Lots are indivisible sets of 25,50 or 100 shares depending on whether the closing price of the security during the previous session is above 5,000 pesetas, between 1,001 and 5,000 pesetas, or below 1,001 pesetas. The minimum price variation is 10,5 or 1 peseta for lots of 25,50 or 100 shares. The maximum price variation is $5 \%$ for the opening price, and an additional $10 \%$ for the regular session.

For the tests reported in Sections 4 and 7, the date and magnitude of all announcements of dividend payments made by any of the 70 stocks are identified by searching the Official Journal of the Madrid Stock Exchange for the period from 2 January 1991 to 18 October 1994. The following selection criteria are employed for the inclusion of a dividend announcement in our sample:

1. We restrict our sample to regular cash dividends payable in pesetas. Any

final, initiation, omission, special or non-recurring dividends are excluded from the sample.

2. If a distribution to stockholders different from cash is made during the period from 10 trading days before to 10 trading days after the announcement of a regular cash dividend, we drop the announcement from the sample. The idea, of course, is to eliminate any confounding impact of stock splits or any kind of non-cash distribution.

3. Under the same line of reasoning, if any change of capital structure is announced from 10 trading days before to 10 trading days after the announcement of a dividend payment, we exclude the announcement from our sample.

4. In order to be incorporated into our sample, at least 3 trading days must elapse between the announcement date and the ex-dividend date.

There are 157 dividend announcements that satisfied the above criteria. Moreover, our sample is divided into three groups depending on whether the 
dividends are higher than, equal to, or lower than dividends paid at (approximately) the same time of the previous year. Hence, in order to classify a dividend payment, we do not compare the magnitude of the dividend to the preceding payment unless the company distributes dividends only once a year. Spanish firms tend to pay dividends of different magnitudes throughout the year. It turns out that, for most cases, we cannot compare two immediately following dividend payments. These figures tend to be very different, and the comparison would not make any sense. Of the 157 announcements, 55 are dividend increases, 26 are dividend decreases, and 76 are unchanged.

\section{Seasonality, trading, and liquidity on the continuous Spanish Stock Exchange Market}

\subsection{Overview}

In this section, we examine the general characteristics of the Spanish market regarding alternative measures of liquidity. Given the well-known evidence that suggests important cross-sectional and time-series differences among size-sorted portfolios, we calculate the average of our measures of liquidity across firms within a size-sorted portfolio.

Descriptive statistics for our five portfolios are contained in Table 1. This table reports the average estimates of relative bid-ask spreads, average depth, average turnover, average volume (total daily number of shares traded), number of transactions, daily portfolio returns, and average estimates of market value (in millions of pesetas).

It is clear that the numbers in Table 1 reflect the strong diversity of firms employed in this analysis. It is surprising that the usual size effect reported in previous studies seems to disappear after 1991 even before risk is adjusted for. ${ }^{6}$ The average market values range from 4,973 million pesetas for the smallest firms to 541,684 million pesetas for the largest stocks. The average daily return is negative for the first group of firms, and becomes positive for large firms. Moreover, there exists a strong cross-sectional variation in trading frequency. The average number of transactions varies from 53 for the smallest firms to 252 for the largest stocks. Similar evidence is found in terms of volume. It is interesting, however, that the number of shares of small firms traded in the market is higher than the number of shares traded in portfolios 2 and 3 . In the same line, turnover is clearly larger for small firms. ${ }^{7}$ Finally, diversity of firms is also found in the average of relative spread and depth. It should be noted that a large depth indicates that there is a higher probability of executing an order against a standing bid or offer. Hence, we would expect a negative correlation between spreads and depths. Lee et al. (1993) are the first authors to perform formal tests on the relation between spreads and depths. For a sample of New York Stock Exchange firms, they show how wide spreads tend to be associated with low depths. ${ }^{8}$ In our sample, we find a negative correlation between both measures of liquidity across all firms of 0.27 . It is surprising, however, that small firms present greater depth than middle-size stocks. In any case, we can infer that on average large companies are more liquid than small companies.

Table 1 also contains some features regarding daily and monthly seasonality of liquidity measures. It is important to notice the large relative spread on Mondays 
and in January for the market as a whole. At the same time, depth and the number of transactions seems to decrease on Mondays. This would suggest that liquidity is lower on Monday than during the rest of the week. On the contrary, depth and the number of transactions tend to be higher during January.

\subsection{Seasonality, trading and liquidity}

Given the potential regularities suggested in the descriptive statistics above, it was decided to carry out more formal tests on seasonality, trading and liquidity in the Spanish continuous auction market.

In order to investigate this issue across portfolios and time, we employ all daily data available from 2 January 1991 to 18 October 1994. The regressions below are estimated by stacking all of the observations and using OLS procedures. In particular, the general form of the regressions is given by:

$$
y_{p t}^{k}=\alpha+\sum_{j=2}^{5} \beta_{j} \mathrm{Dmval}_{j t}+\sum_{m=2}^{5} \delta_{m} \mathrm{Dwk}_{\mathrm{mt}}+\gamma \text { Dry }_{\mathrm{t}}+\varepsilon_{\mathrm{pt}}
$$

where $y_{p r}^{k}$ is the cross-sectional mean of characteristic $k$ for assets belonging to portfolio $p$ during day $t$, and $\mathrm{Dmval}_{j i}, \mathrm{Dwk}_{m i}$, and Dry, are dummy variables for size, day of the week, and the rest of the year. The results are reported for the relative bid-ask spread, ${ }^{9}$ depth, turnover, volume, transactions, returns and volatility (squared returns). It is important to point out that the portfolio containing

\section{Table 1}

Measures of liquidity.

Stocks are assigned to five portfolios based on the market value of their equity at the end of each year. Mvall contains the stocks with the smallest market capitalisation, and Mval5 contains the stocks with the largest market capitalisation. Portfolios are equally weighted. The bid-ask spread is the percentage bid-ask spread based on the average of the five best bids and the five best offers of each trading day. The depth is the number of shares available at each price, again as the average of the five best selling and buying positions in the market during each trading day. Turnover is defined as the number of shares traded during each day divided by the number of shares outstanding. Volume is the number of shares traded per day. Transactions represent the number of transactions in each day. Data are available from 2 January 1991 to 10 October 1994. All figures represent averages over the full period.

\begin{tabular}{lcrcrrrr}
\hline Portfolios & $\begin{array}{c}\text { Bid-ask } \\
\text { spread* } \\
(\%)\end{array}$ & Depth & $\begin{array}{c}\text { Turnover } \\
(\%)\end{array}$ & Volume & Transactions & $\begin{array}{r}\text { Return } \\
(\%)\end{array}$ & $\begin{array}{c}\text { Market } \\
\text { value } \\
\text { (millions) }\end{array}$ \\
\hline MVAL1 & 2.221 & 5332 & 0.534 & 69752 & 53 & -0.019 & 4973 \\
MVAL2 & 1.710 & 3523 & 0.256 & 56288 & 58 & -0.008 & 19701 \\
MVAL3 & 1.471 & 2553 & 0.214 & 49855 & 67 & 0.020 & 49687 \\
MVAL4 & 0.835 & 5969 & 0.198 & 185420 & 129 & 0.034 & 112477 \\
MVAL5 & 0.464 & 19472 & 0.152 & 401356 & 252 & 0.047 & 541684 \\
Market & 1.340 & 7370 & 0.271 & 152534 & 112 & 0.021 & - \\
January & 1.537 & 7698 & 0.297 & 163031 & 132 & 0.391 & - \\
Other months & 1.323 & 7340 & 0.269 & 151579 & 110 & -0.012 & - \\
Monday & 1.510 & 6921 & 0.248 & 129927 & 107 & 0.058 & - \\
Other days & 1.300 & 7483 & 0.277 & 158230 & 113 & 0.012 & \\
\hline
\end{tabular}

$*($ Ask - Bid $) /[($ Ask + Bid $) / 2]$. 
the smallest firms, Monday, and January are the control variables in the regressions. Lehmann and Modest (1994) employ a similar set of regressions, but in order to avoid linear dependency among the independent variables, they impose the constraint that all within-group dummy variable coefficients sum to zero. In this paper, given the particular behaviour of small firms and either daily or monthly seasonality, it was decided to use control variables. All our results are therefore presented relative to these variables. Finally, $t$-statistics reported are based on Newey-West consistent standard errors.

The empirical results are contained in Table 2 . The evidence tends to confirm some of the results already suggested in Table 1. Small stocks tend to have significantly larger percentage spreads, and higher turnover and volatility than large stocks. At the same time, they have less depth, volume and transactions than the largest stocks in the sample. However, we find a J-pattern across sizesorted portfolios for depth and volume. If we measure liquidity by simultaneously the percentage spread and depth, we may conclude that small firms are less liquid than firms in the two upper size quintiles of the market.

On the other hand, the percentage spread is significantly higher on Monday than in any of the other days of the week. A reversed pattern is found for depth. It seems that Monday presents a significantly lower liquidity than during the rest of the week. Moreover, turnover, volume and transactions are significantly lower on Mondays than for the rest of the week. It should also be noted that volatility seems to be higher on Mondays. Finally, relative spreads, turnover, transactions, average returns and volatility are higher in January than in the rest of the year. However, depth is not significantly different in January than in the rest of the year. It is difficult to reconcile the larger relative spread of January with other intuitive measures of liquidity and trading.

Four three-dimensional graphs contain further evidence related to seasonality and liquidity across our five portfolios. Figure 1 presents the average relative bid-ask spread for stocks in our five size-sorted portfolios over the days of the week. As we already know, the relative spread is a monotonic function of firm size with the spread largest for the smallest stocks. It is interesting that this pattern holds over all days of the week. At the same time, we can appreciate that the percentage spread is also a monotonic function of days of the week; the largest spread occurs on Mondays, independently of the size-sorted portfolio. Figure 2 is a similar three-dimensional graph, where we include depth rather than relative spread. It is more difficult to observe a clear pattern across days of the week. Depth, however, seems to be lower for larger companies on Mondays. At the same time, we observe the $J$-pattern across our five size-sorted portfolios for every day of the week. Figures 3 and 4 contain a similar type of evidence regarding January and the rest of the year. The monotonic function of firm size with the relative spread is preserved for January and for the rest of the year. Moreover, independently of the portfolio observed, the relative spread is always higher in January. Figure 4 maintains the $J$-pattern for depth across portfolios, and shows a very similar depth across all months of the year.

Intriguing patterns of alternative measures of liquidity and trading have been found in the Spanish continuous auction market. Research directed toward the explanation of these patterns is clearly justified and is left for future papers.

We are now in a position to investigate potential changes in the compensation of adverse selection and market liquidity around dividend announcements. 


\section{Dividend announcements and market liquidity: univariate empirical evidence}

It is well known that dividend signalling theories suggest that dividends convey information about managers' expectations regarding the future prospects of the firm. ${ }^{10}$ Several papers have reported significant price reactions to dividend changes. ${ }^{11}$ Therefore, it seems reasonable that if the bid-ask spread incorporates an adverse information component, we would expect to find changes in spread during periods of dividend announcements. Hence, dividend announcements are a particularly well suited strategy for analysing the effect of changes in information asymmetry.

\section{Table 2}

Measures of liquidity.

Stocks are assigned to five portfolios based on the market value of their equity at the end of each year. Mval1 contains the stocks with the smallest market capitalisation, and Mval5 contains the stocks with the largest market capitalisation. Portfolios are equally weighted. The bid-ask spread is the percentage bid-ask spread based on the average of the five best bids and the five best offers of each trading day. The depth is the number of shares available at each price, again as the average of the five best selling and buying positions in the market during each trading day. Turnover is defined as the number of shares traded during each day divided by the number of shares outstanding. Volume is the number of shares traded per day. Transactions represent the number of transactions in each day. Data are available from 2 January 1991 to 10 October 1994. All figures are estimated by stacking all of the observations and using OLS regressisons of the following form:

$$
y_{p t}^{k}=\alpha+\sum_{j=2}^{5} \beta_{j} \text { Dmval }_{l t}+\sum_{m=2}^{5} \delta_{m} \text { Dwk }_{m t}+\gamma \text { Dry }_{i}+\varepsilon_{p t}
$$

where $y_{p t}^{k}$ is the cross-sectional mean of characteristic $k$ for assets belonging to portfolio $p$ during day $t$, and Dmval ${ }_{j}$, Dwk ${ }_{m}$, Dry $y_{i}$ are dummy variables for size, day of the week and rest of the year. Mval1, Monday, and January are the control variables. Newey-West standard errors are employed.

\begin{tabular}{|c|c|c|c|c|c|c|c|}
\hline Characteristic & $\begin{array}{c}\text { Bid-ask } \\
\text { spread* } \\
(\%)\end{array}$ & Depth & $\begin{array}{c}\text { Turnover } \\
(\%)\end{array}$ & Volume & Transactions & $\begin{array}{c}\text { Return } \\
(\%)\end{array}$ & $\begin{array}{c}\text { Squared } \\
\text { returns } \\
(\%)\end{array}$ \\
\hline \multirow[t]{2}{*}{ Constant } & 2.586 & 5213 & 0.537 & 57608 & 69 & 0.506 & 0.059 \\
\hline & $(33.28)$ & (9.54) & $(23.41)$ & (6.56) & $(14.30)$ & $(4.18)$ & (10.50) \\
\hline \multirow[t]{2}{*}{ MVAL2 } & -0.511 & -1809 & -0.277 & -13465 & 5.22 & 0.011 & -0.012 \\
\hline & $(-8.82)$ & $(-8.70)$ & $(-14.39)$ & $(-4.04)$ & $(2.55)$ & $(0.14)$ & $(-3.51)$ \\
\hline \multirow[t]{2}{*}{ MVAL3 } & -0.750 & -2779 & -0.320 & -19897 & 13.91 & 0.039 & -0.016 \\
\hline & $(-13.12)$ & $(-16.31)$ & $(-17.23)$ & $(-6.49)$ & $(6.27)$ & $(0.50)$ & $(-4.89)$ \\
\hline \multirow[t]{2}{*}{ MVAL4 } & -1.386 & 637 & -0.336 & 115667 & 77.55 & 0.053 & -0.020 \\
\hline & $(-27.39)$ & (3.63) & $(-18.23)$ & $(21.31)$ & $(28.55)$ & $(0.70)$ & $(-6.63)$ \\
\hline \multirow[t]{2}{*}{ MVAL5 } & -1.757 & 14140 & -0.382 & 331604 & 199.01 & 0.067 & -0.023 \\
\hline & $(-37.89)$ & $(30.86)$ & $(-20.97)$ & $(35.81)$ & $(43.25)$ & $(0.91)$ & $(-8.23)$ \\
\hline \multirow[t]{2}{*}{ Tuesday } & -0.237 & 524 & 0.026 & 21557 & 5.68 & -0.073 & -0.011 \\
\hline & $(-5.83)$ & $(2.76)$ & $(3.22)$ & $(4.50)$ & $(2.75)$ & $(-1.02)$ & $(-3.38)$ \\
\hline \multirow[t]{2}{*}{ Wednesday } & -0.210 & 683 & 0.034 & 27108 & 4.94 & -0.243 & -0.010 \\
\hline & $(-4.65)$ & $(2.82)$ & $(3.28)$ & $(5.49)$ & (1.93) & $(-3.46)$ & $(-3.08)$ \\
\hline \multirow[t]{2}{*}{ Thursday } & -0.177 & 458 & 0.029 & 30669 & 4.73 & -0.082 & -0.007 \\
\hline & $(-3.77)$ & $(2.05)$ & $(2.98)$ & (5.93) & $(1.78)$ & $(-1.12)$ & $(-1.96)$ \\
\hline \multirow[t]{2}{*}{ Friday } & -0.225 & 580 & 0.027 & 34085 & 6.22 & 0.029 & -0.015 \\
\hline & $(-5.42)$ & $(2.90)$ & (3.49) & (7.14) & (2.87) & $(0.45)$ & $(-4.52)$ \\
\hline \multirow[t]{2}{*}{ Rest of year } & -0.214 & -359 & -0.028 & -11408 & -22.41 & -0.492 & -0.017 \\
\hline & $(-3.47)$ & $(-0.65)$ & $(-1.93)$ & $(-1.35)$ & $(-4.88)$ & $(-5.34)$ & $(-3.92)$ \\
\hline
\end{tabular}


Unfortunately, previous studies have mostly concentrated on earnings announcements, and they have been carried out in the continuous dealer market case. In fact, to the best of our knowledge, this is the first study of changes in information asymmetry within the context of a continuous auction market. Moreover, the work of Morse and Ushman (1983), Venkatesh and Chiang (1986), Skinner (1991), Barclay and Dunbar (1991), and Daley et al. (1991) tends to find contradictory evidence that is very difficult to interpret. The most complete and careful analysis regarding the effect of earnings announcements on market liquidity is that published by Lee et al. (1993). They convincingly argue that spreads widen and depths fall whenever market participants anticipate earnings announcements. They also show that these effects are more pronounced for announcements with the larger subsequent price move. They conclude that during the days prior to earnings announcements and during the event interval there exists an unambiguous decrease in liquidity.

The reasoning by which they explain their results may be extrapolated to dividend announcements. It may be argued that the timing throughout the year of both earnings and dividends announcements is largely predictable. Thus, in a continuous auction mechanism, if liquidity providers anticipate a greater probability of trading against informed investors in advance of dividend announcements, the adverse selection model would imply a wider bid-ask spread. In terms of market liquidity, under similar circumstances, it seems also reasonable to predict a smaller depth. Of course, if the timing of dividend

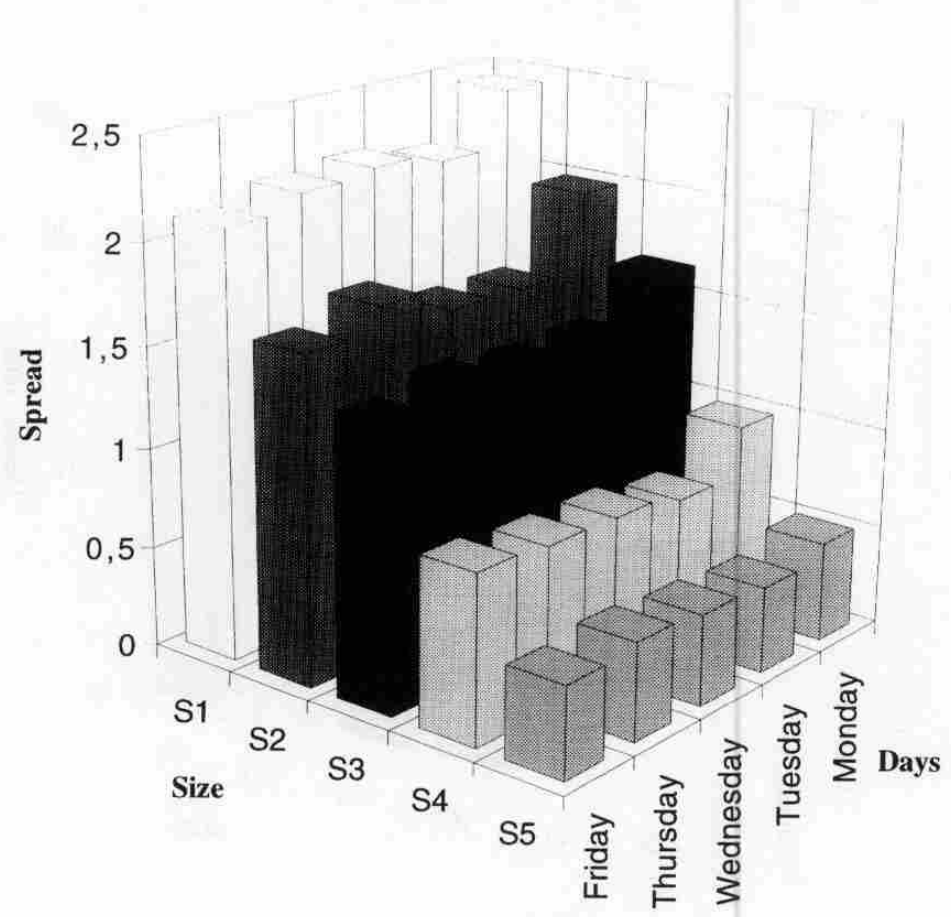

Fig. 1. Bid-ask spreads for stocks sorted by size. 
announcements is not predictable, and there are no leakages prior to the arrival of new information, we should not expect to find any impact on spread.

Although, given the characteristics of dividend payments, it may be reasonable to expect an increase in information asymmetry before dividend announcements, the predictions for the announcement and even for the beginning of the postannouncement periods may depend upon how noisy the signal transmitted to the market is. If a dividend announcement may be regarded as a non-noisy signal, given that managers are better informed than outsiders, the information content of dividends reduces information asymmetries among traders, and consequently, we should expect a lower bid-ask spread.

On the other hand, if dividend announcements may be interpreted as noisy signals (as earnings are), it should be taken into account that insiders are more able to understand the news conveyed by the announcement. This is the point raised by Kim and Verrecchia (1994) regarding earnings announcements. Independently of trading volume, these authors argue that noisy signals stimulate informed judgements. If this is the case, we may expect higher information asymmetry after the announcements, and consequently, a wider bid-ask spread should be found.

In order to investigate the impact of dividend announcements on market liquidity for each of the four characteristics employed in the analysis (spread, defined as the difference between the ask price and the bid price, depth, volume

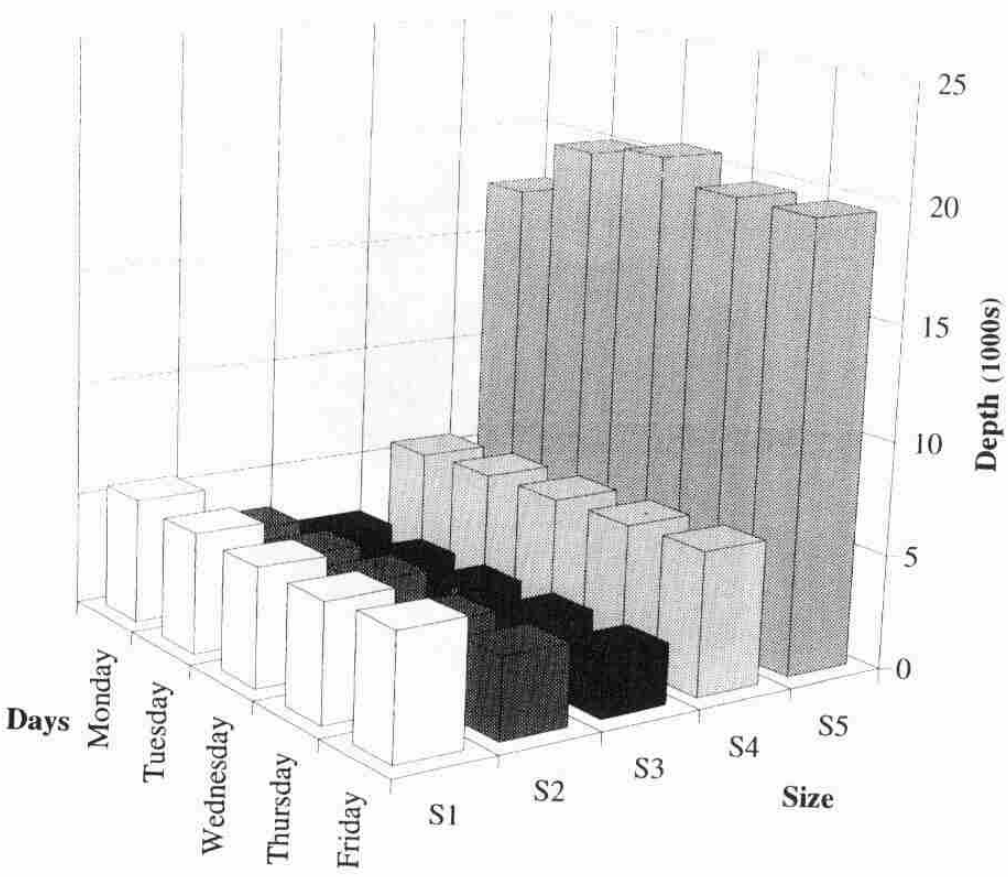

Fig. 2. Depth for stocks sorted by size. 
and number of transactions), we divide every observation in the sample period by the average of its corresponding day of the week. In other words, if the particular observation turns out to be for Monday, then this observation is divided by the average of the analysed characteristic for Mondays. The same procedure is followed for the rest of the week. This should take into account the strong seasonality found in our alternative measures of liquidity. Moreover, all variables are expressed as percentage deviations from the daily seasonal adjusted mean value of the characteristic being studied. It is important to realise that this procedure is repeated for each individual firm with a dividend announcement during the sampling period.

In particular, we calculate the following statistics for all firms in the sample:

$$
K_{t}=\left(\frac{S_{t}}{\bar{S}_{(t)}}-1\right) \times 100
$$

where $K_{t}$ is the characteristic being analysed (spread, depth, volume or transactions), $S_{t}$ is the actual liquidity statistic during day $t$ (spread in day $t$, depth in day $t$, etc.), and $\bar{S}_{(t)}$ is the average of the liquidity statistic for the corresponding day of the week.

Finally, the average of $K_{t}$ across all announcements is calculated from day -10 to day +10 around the event. The cross-sectional distribution of this

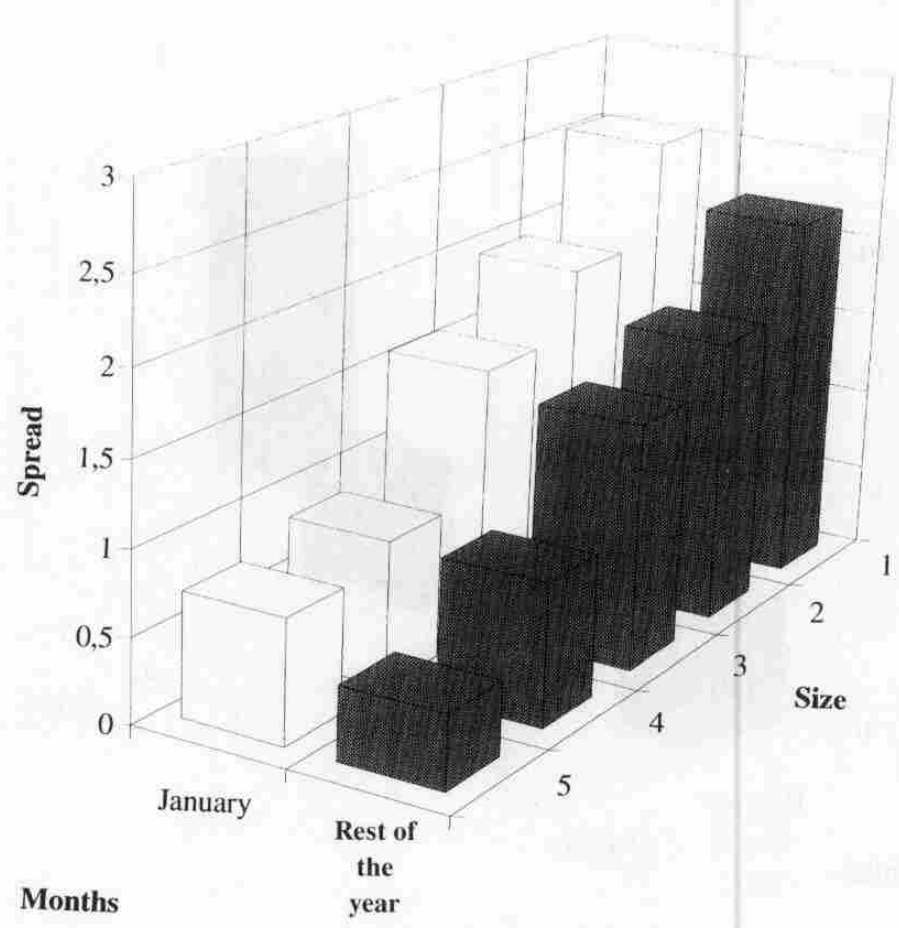

Fig. 3. Bid-ask spreads for stocks sorted by size. 
average is used to study the significance of the event. ${ }^{12}$ At the end, we have the percentage changes in spread, depth, volume and number of transactions around dividend announcements.

The empirical results are contained in Table 3 . The evidence seems strikingly consistent with changes in information asymmetry during the day immediately before the event, and during the day of the announcement. The spread decreases by $12.4 \%$ during event time, and the reduction is significantly different from zero. It seems that dividends convey precise information about the firm, so that the adverse selection component of spread is clearly reduced. Therefore, information asymmetry risks tend to disappear whenever there is a dividend announcement. It should be noted that the official announcement of all dividend payments employed in the article is made at some point during event day zero.

The second column of Table 3 reports similar statistics for depth. Interestingly, the results are not significantly different from zero. There is some evidence, however, that percentage changes in depth tend to be positive. In any case, dividend announcements do not seem to imply unambiguous changes in market liquidity.

The last two columns in this table suggest that percentage changes in volume and transactions are positive around the event. In particular, there exists a significant and positive reaction of the number of transactions during days -1 and 0 . The number of transactions increases by $15.3 \%$ on these days. This is an

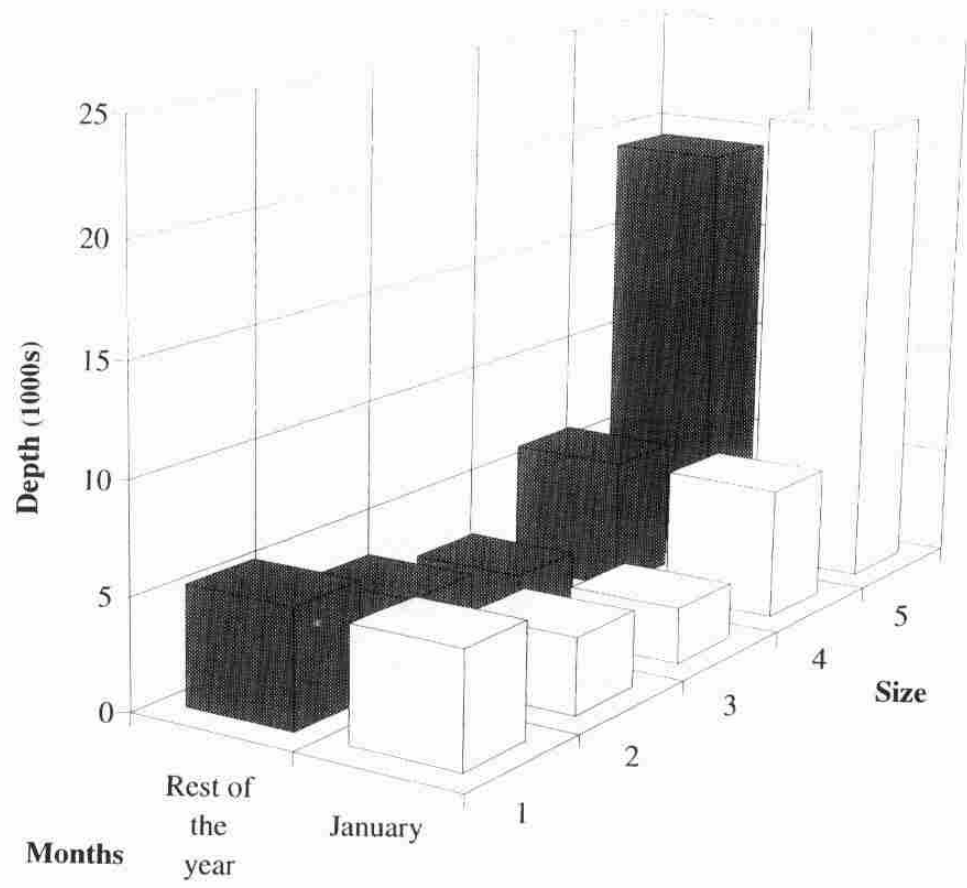

Fig. 4. Depth for stocks sorted by size. 
important point and, as we will see later in the paper, it will have serious consequences for the interpretation of the results.

Figure 5 shows the cumulative percentage changes around event time for the four characteristics employed in the analysis. It can be observed that spread tends to decrease around the announcements, whilst volume and transactions move in the opposite direction. There can also be appreciated a small jump in depth during the days immediately before the event. Both Table 3 and Fig. 5 suggest that changes in spread around the announcements may tend to disappear if we check for the simultaneous effect on either volume or transactions. We will come back to this important issue in Section 7.

Table 3

Percentage changes in spread, depth, volume and number of transactions around dividend announcements.

For each of the four characteristics employed in the analysis (spread, depth, volume and number of transactions), $w-$ divide each observation in the sample period by the average of its corresponding day of the week. In particular we calculated the following statistics for all firms in the sample:

$$
K_{t}=\left(\frac{S_{f}}{\tilde{S}_{(\ell)}}-1\right) \times 100
$$

where $K_{t}$ is the characteristics being analysed, $S_{1}$ is the actual liquidity statistic during day $t$, and $\bar{S}_{(t)}$ is the average of the liquidity statistic for the corresponding day of the week. From day -10 to day +10 around the event, the average of $K_{t}$ across all announcements is calculated. The cross-sectional distribution of this average is used to study the significance of the event. White standard errors are used. $t$-statistics are presented in parentheses. Results for the complete sample of dividend announcements are reported.

\begin{tabular}{ccccc}
\hline $\begin{array}{c}\text { Days around } \\
\text { announcement }\end{array}$ & Spread $^{*}$ & Depth** & Volume*** & Transactions \\
\hline-4 & -5.22 & 1.02 & 27.06 & 5.58 \\
-3 & $(-0.84)$ & $(0.12)$ & $(0.91)$ & $(1.13)$ \\
& -2.26 & 0.35 & 19.29 & -0.21 \\
-2 & $(-0.22)$ & $(0.06)$ & $(0.76)$ & $(-0.05)$ \\
& -5.80 & 22.55 & 54.76 & 0.57 \\
-1 & $(-0.95)$ & $(0.96)$ & $(1.35)$ & $(0.12)$ \\
& -11.60 & 1.03 & 7.12 & 15.30 \\
0 & $(-2.56)$ & $(0.25)$ & $(0.84)$ & $(2.30)$ \\
& -12.37 & 6.70 & 26.47 & 15.33 \\
+1 & $(-3.15)$ & $(0.86)$ & $(1.62)$ & $(2.14)$ \\
& 2.56 & 0.49 & -0.63 & 6.83 \\
+2 & $(0.37)$ & $(0.09)$ & $(-0.09)$ & 6.35 \\
+3 & -8.37 & 2.85 & 7.80 & $(1.25)$ \\
& $(-1.76)$ & $(0.41)$ & $(0.72)$ & 2.59 \\
+4 & -3.74 & -1.36 & 5.19 & $(0.51)$ \\
& $(-0.65)$ & $(-0.29)$ & $(0.48)$ & 2.93 \\
& 9.41 & -5.12 & -7.70 & $(0.53)$ \\
\hline
\end{tabular}

${ }^{*}$ Spread $=$ Ask - Bid.

*** Depth $=$ Depth at ask + Depth at bid.

****Volume is number of shares traded. 


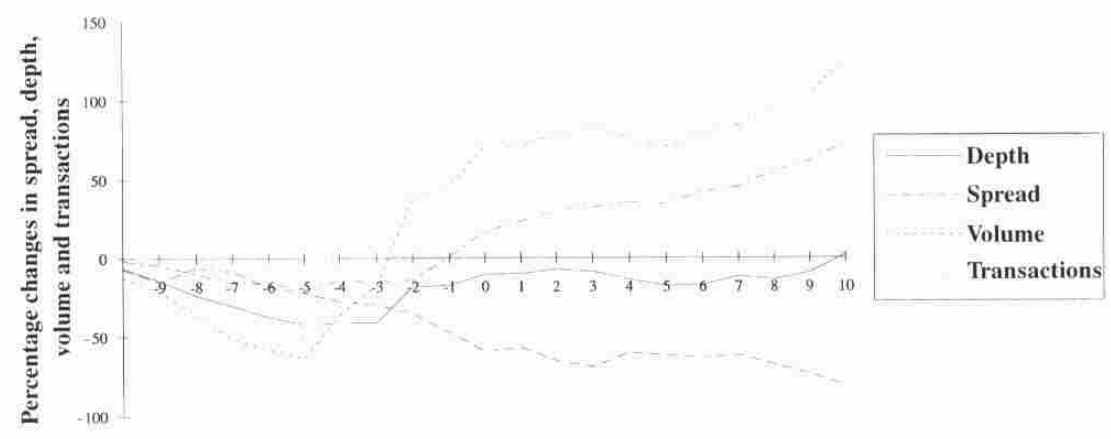

Days

Fig. 5. Measures of liquidity around dividend announcements.

The results in Table 4 are partitioned according to whether the dividend is increased, maintained, or decreased relative to the previous payment over the (approximately) same time of the year before the announcement. As before, the evidence is consistent with changes in information asymmetry risks. In terms of spread, the major impact occurs for maintained and decreased dividends. There are significant reductions in the spread of both groups of stocks during the day before the event, and on the day of the dividend announcement. The spread for companies announcing less dividends diminishes by almost $24 \%$. It seems that a signal corroborating negative proposals for the companies eliminates potential information asymmetries. This would be reflected in the significant reduction of spread. On the other hand, the enormous increase in volume and transactions around decreased dividend announcements should be pointed out. Once again, the results regarding changes in spread may simply reflect the confounding effects of either volume or transactions.

Finally, percentage changes in depth are not significantly different from zero during event time. However, in the case of increased dividends, there seem to be significant reductions in depth during the days immediately after the event. Interestingly, the reverse pattern is found for decreased dividend announcements.

In general, our results might be interpreted in favour of liquidity providers being sensitive to changes in information asymmetry risks. Unfortunately, however, it may be the case that spread and either volume or transactions are negatively related. This may alter the interpretation of the results. The specific relation between spreads, volume, and transactions is investigated next.

\section{The relation between spreads, volume and transactions}

Unlike the extensive existing cross-sectional evidence between spreads, volume and the number of transactions, ${ }^{13}$ evidence related to the time-series relation between these variables is very limited. In fact, within a continuous dealer market, the first paper dealing directly with this issue was recently published by Lee et al. (1993). It should be noted, however, that their evidence is exclusively directed toward the temporal relation between spread (and depth) and volume. 
Table 4

Percentage changes in spread, depth, volume and number of transactions around dividend announcements classified according to the change in the dividend payment.

For each of the four characteristics employed in the analysis (spread, depth, volume and number of transactions), we divide each observation in the sample period by the average of its corresponding day of the week. In particular we calculated the following statistics for all firms in the sample:

$$
K_{\mathrm{r}}=\left(\frac{S_{t}}{\bar{S}_{(0)}}-1\right) \times 100
$$

where $K_{t}$ is the characteristics being analysed, $S_{r}$ is the actual liquidity statistic during day $\iota_{l}$ and $\bar{S}_{i}$ is the average of the liquidity statistic for the corresponding day of the week. From day -10 to day +10 around the event, the average of $K_{t}$ across all announcements is calculated. The cross-sectional distribution of this average is used to study the significance of the event. White standard errors are used. $t$-statistics are presented in parentheses. Results are reported separately according to the change in the dividend payment.

\begin{tabular}{|c|c|c|c|c|c|c|c|c|c|c|c|c|}
\hline \multirow[t]{2}{*}{ Days } & \multicolumn{4}{|c|}{ Increased dividends } & \multicolumn{4}{|c|}{ Maintained dividends } & \multicolumn{4}{|c|}{ Decreased dividends } \\
\hline & Spread* & Depth** & Volume $e^{* * *}$ & Transt & Spread & Depth & Volume & Trans & Spread & Depth & Volume & Trans \\
\hline \multirow[t]{2}{*}{-4} & -5.47 & -13.67 & -9.98 & -1.00 & 5.71 & 10.34 & 59.11 & 5.17 & -36.63 & 4.83 & 11.70 & 20.71 \\
\hline & $(-0.66)$ & $(-2.87)$ & $(-1.16)$ & $(-0.14)$ & $(0.52)$ & $(0.62)$ & $(0.97)$ & $(0.70)$ & $(-6.48)$ & $(0.41)$ & $(0.58)$ & $(1.47)$ \\
\hline \multirow[t]{2}{*}{-3} & 14.99 & -2.25 & 51.61 & -4.35 & -7.29 & 4.03 & 1.58 & -3.81 & -24.09 & -4.89 & 2.73 & 19.06 \\
\hline & $(0.57)$ & $(-0.16)$ & $(0.76)$ & $(-0.75)$ & $(-0.93)$ & $(0.58)$ & $(0.10)$ & $(-0.60)$ & $(-3.38)$ & $(-0.72)$ & $(0.16)$ & $(1.41)$ \\
\hline \multirow[t]{2}{*}{-2} & -8.27 & -1.65 & 37.21 & -1.55 & -1.95 & 44.53 & 76.39 & -2.41 & -11.82 & 9.50 & 28.65 & 13.75 \\
\hline & $(-0.84)$ & $(-0.15)$ & $(0.77)$ & $(-0.24)$ & $(-0.20)$ & $(0.94)$ & $(1.01)$ & $(-0.34)$ & $(-1.14)$ & $(1.29)$ & $(1.00)$ & (1.01) \\
\hline \multirow[t]{2}{*}{-1} & -9.09 & -7.73 & -7.68 & -1.35 & -11.78 & 6.57 & 6.43 & 12.03 & -16.40 & 3.41 & 40.45 & 60.11 \\
\hline & $(-1.08)$ & $(-1.21)$ & $(-0.78)$ & $(-0.21)$ & $(-1.87)$ & (1.03) & $(0.52)$ & $(1.42)$ & $(-1.71)$ & $(0.39)$ & (1.39) & $(2.25)$ \\
\hline \multirow[t]{2}{*}{0} & -8.79 & -8.42 & 11.46 & 3.41 & -11.02 & -0.84 & 10.37 & 0.32 & -23.87 & 60.75 & 105.28 & 55.17 \\
\hline & $(-1.35)$ & $(-1.21)$ & $(0.45)$ & $(0.52)$ & $(-1.87)$ & $(-0.12)$ & $(0.77)$ & (1.11) & $(-2.88)$ & $(1.59)$ & (1.49) & (1.87) \\
\hline \multirow[t]{2}{*}{+1} & -7.00 & -16.61 & -11.05 & -6.17 & 11.82 & 6.04 & -0.63 & 7.20 & -4.27 & 20.44 & 21.38 & 33.29 \\
\hline & $(-0.98)$ & $(-3.21)$ & $(-1.24)$ & $(-1.02)$ & $(0.97)$ & $(0.74)$ & $(-0.07)$ & $(1.01)$ & $(-0.28)$ & (1.14) & $(0.81)$ & $(1.73)$ \\
\hline \multirow{2}{*}{+2} & -1.58 & -9.14 & 15.51 & -8.13 & -9.89 & -0.99 & -0.40 & 10.83 & -18.32 & 39.43 & 15.47 & 23.91 \\
\hline & $(-0.18)$ & $(-1.65)$ & $(0.64)$ & $(-1.09)$ & $(-1.44)$ & $(-0.17)$ & $(-0.03)$ & (1.51) & $(-2.13)$ & (1.12) & $(0.68)$ & (1.58) \\
\hline \multirow{2}{*}{+3} & 2.27 & -18.44 & -6.82 & -11.82 & -6.53 & 4.11 & -3.56 & 8.20 & -8.29 & 18.83 & 56.19 & 16.69 \\
\hline & $(0.29)$ & $(-3.42)$ & $(-0.37)$ & $(-1.66)$ & $(-0.68)$ & $(0.57)$ & $(-0.30)$ & (1.10) & $(-0.68)$ & $(1.46)$ & (1.48) & (1.11) \\
\hline \multirow[t]{2}{*}{+4} & 34.46 & -15.10 & -11.95 & -10.20 & -3.99 & -4.59 & -5.92 & 10.15 & -4.42 & 14.45 & -3.90 & 9.62 \\
\hline & (1.06) & $(-3.21)$ & $(-1.19)$ & $(-1.47)$ & $(-0.37)$ & $(-0.72)$ & $(-0.70)$ & $(1.23)$ & $(-0.34)$ & (1.25) & $(-0.21)$ & $(0.58)$ \\
\hline
\end{tabular}

${ }^{*}$ Spread $=$ Ask - Bid. ${ }^{* *}$ Depth $=$ Depth at ask + Depth at bid. ${ }^{* * *}$ Volume is number of shares traded. $\mp$ Trans is the number of transactions. 
They ignore the potential effects of the number of transactions. It turns out, as we will discuss in this section, that the apparently strong relation between spread and volume is cancelled out whenever we control for the number of transactions.

From a theoretical point of view we have, as discussed by Lee et al., two relevant and competing hypotheses that may help us to understand the relation between these variables. Easley and O'Hara (1992) argue that the stochastic process of prices depends on time per se and volume. Hence, in their model, it is volume as of a particular time $t$ that influences the distribution of prices over the next period. This implies that volume becomes a signal for the market maker. A large volume is equivalent to a greater probability of facing informed traders. Therefore the specialist widens spread to compensate for the additional adverse selection. Thus, their model predicts a positive relation between spread and volume in a time-series framework.

On the other hand, Harris and Raviv (1993) suggest a model in which agents receive the same information. However, these agents differ in the way in which they understand this common information. Volume shocks are simply a consequence of the lack of agreement among participants in the market. This context implies that higher volume should be related to liquidity providers sending limit orders in both sides of the market as a result of differences on opinion. This may tend to reduce the bid-ask spread. ${ }^{14}$

Given these arguments, it seems that the time-series relation between spread and volume should be empirically analysed. This is exactly what Lee et al. (1993) do. Interestingly, one may suggest that these models reflect primarily a relation between the number of transactions and the spread. This is the case given that, in both models, the size of each transaction is normalised to unity. Nevertheless, what we really may affirm is that their models cannot distinguish between volume and the number of transactions. Again, empirically documented evidence should be employed to infer whether the time-series relation is dominated by either volume or transactions.

In order to investigate this issue, the following time-series regression is run for each stock in the sample with daily data from 2 January 1991 to 18 October 1994:

$$
\text { Spread }_{t}=\alpha+\beta_{1} N V_{t}+\beta_{n} N N_{t}+\eta_{t}
$$

where the spread variable is given by:

$$
\left(\frac{S P_{t}}{S \bar{P}_{(t)}}-1\right) \times 100
$$

where $S P_{t}$ is the actual spread during day $t$, and $S \bar{P}_{(t)}$ is the average spread for the corresponding day of the week over the whole period. The normalised volume $(N V)$ and normalised transactions $(N N)$ are given by:

$$
N V_{t}=\sqrt{\frac{V O L_{t}}{V \bar{O} L_{(t)}}} ; \quad N N_{t}=\sqrt{\frac{N_{t}}{\bar{N}_{(t)}}}
$$

where $V O L_{t}$ is the number of shares traded in each stock during day $t, N_{t}$ represents the number of transactions of each stock during day $t$, and $V \bar{O} L_{(t)}$ and 
$\bar{N}_{(t)}$ are, as before and respectively, the average of volume and transactions for their corresponding day of the week. It should be pointed out that the distributions of the explanatory variables are highly skewed. Thus, the square roots of the variables are employed so that outliers do not dominate the empirical evidence. Moreover, given that the residuals from OLS regressions are mostly significantly autocorrelated, the regressions are repeated with an autoregressive term, and using the well known procedure suggested by Cochrane-Orcutt. Both types of adjustments produce identical qualitative results.

Table 5 reports the results. The coefficients contained in the table are the cross-sectional average of all individual regressions. In parenthesis, we report the $t$-statistics under the null hypothesis that the cross-sectional mean of the coefficients equals zero. White-consistent standard errors are used.

The results show a very strong negative relation between volume and spreads. In our time-series framework this suggests that, in the continuous auction Spanish market, spreads tend to be smaller during periods of higher volume. This is exactly contrary to the evidence reported by Lee et al. for the US market. At the same time, it turns out that there exists an even stronger negative relation between transactions and spreads. This empirical evidence seems, therefore, consistent with the Harris and Raviv (1993) prediction that spreads and either (in their model) volume or transactions are negatively associated.

The most striking result of Table 5 is that the significant negative relation between volume and spreads tends to be cancelled out when we include simultaneously volume and the number of transactions in the regressions. The strong negative relation between transactions and spreads is maintained, but the negative association between volume and spreads becomes statistically insignificant. This is an important result, and it to a certain extent justifies microstructure theoretical models in which all trades are normalised to be of unit size. It may be argued that we should have employed the average trade size rather than the total number of shares as an explanatory variable. This would be the most natural decomposition of the effects of volume on spreads. Of course, volume is the average trade size times the number of transactions. However, it was decided to keep volume so that we are able to provide a direct comparison with the results obtained by Lee et al. Moreover, we may have a multicollinearity problem in the regressions given by equation (3). The range of the correlation coefficients between the normalised volume and the normalised number of transactions for each firm in the sample goes from 0.40 to 0.90 . It must be pointed out that, in all cases, independently of the correlation coefficient, the effect of volume disappears when the number of transactions is taken into account.

We may conclude that spreads tend to decrease during periods of higher number of transactions. In the context of the Harris and Raviv (1993) model, we may argue that the increased number of transactions primarily denotes an increase in liquidity trading through public limit orders. In fact, when we regress the percentage change of depth on the normalised number of transactions, it is found that there is a positive, significant relation between depth and transactions. This clearly suggests that market liquidity tends to increase with the number of transactions. ${ }^{15}$

This result naturally leads towards further investigation of the number of transactions as a key aspect of the process of stock price adjustments. This is the next issue looked at in this paper. 


\section{The relation between volatility, volume and transactions}

One way in which we may justify the importance of the number of transactions within an empirical context of asset pricing is by analysing the relation between transactions and volatility.

Both the theoretical models and empirical work related to information effects on asset pricing have generally accepted the popular view that it takes volume to move prices'. In particular, microstructure theory under asymmetric information suggests that informed traders send small-sized trades in order to avoid losing their comparative advantage. ${ }^{16}$ This view assumes that the information

\section{Table 5}

The relation between volume, number of transactions and spread.

For each stock in the sample, a time-series regression is run with spread as the dependent variable and volume, the number of transactions or both as the independent variables. In particular, for each stock the following regression with daily data from January 1991 to October 1994 is performed:

$$
\text { Spread }_{t}=\alpha+\beta_{1} N V_{t}+\beta_{n} N N_{t}+\eta_{t}
$$

where the spread variable is given by:

$$
\left(\frac{S P_{r}}{S \bar{P}_{(t)}}-1\right) \times 100
$$

where $S P_{1}$ is the actual spread during day $t$, and $S \bar{P}_{(\ell)}$ is the average of the spread for the corresponding day of the week. The normalised volume $(N V)$ and normalised transactions $(N N)$ are given by:

$$
N V_{t}=\sqrt{\frac{V O L_{t}}{V \bar{O} L_{i(t)}}} ; \quad N N_{t}=\sqrt{\frac{N_{i}}{\bar{N}_{(i)}}}
$$

The reported coefficients are the cross-sectional average across all stocks in the sample. In parentheses we report the $t$-statistics under the null hypothesis that the cross-sectional mean of the coefficients is zero.

\begin{tabular}{|c|c|c|c|}
\hline \multicolumn{4}{|c|}{ Panel B: Regressions with Cochrane-Orcutt iterations } \\
\hline & $\alpha$ & $\beta_{r}$ & $\beta_{n}$ \\
\hline Model 1 (Volume) & $\begin{array}{c}30.48 \\
(11.22)\end{array}$ & $\begin{array}{c}-35.53 \\
(-11.91)\end{array}$ & - \\
\hline Model 2 (Transactions) & $\begin{array}{c}63.53 \\
(12.26)\end{array}$ & - & $\begin{array}{r}-68.77 \\
(-12.63)\end{array}$ \\
\hline Model 3 (Both) & $\begin{array}{c}64.16 \\
(11.88)\end{array}$ & $\begin{array}{c}-0.63 \\
(-0.28)\end{array}$ & $\begin{array}{l}-69.89 \\
(-10.96)\end{array}$ \\
\hline
\end{tabular}

Panel A: Regressions with no correction for serial autocorrelations in the residuals

\begin{tabular}{lccc} 
& $\alpha$ & $\beta_{i}$ & $\beta_{n}$ \\
\hline Model 1 (Volume) & 33.92 & -39.25 & - \\
Model 2 (Transactions) & $(10.34)$ & $(-10.77)$ & -65.60 \\
Model 3 (Both) & 60.99 & - & $(-10.51)$ \\
& $(10.30)$ & -4.70 & -61.37 \\
& 61.21 & $(-0.97)$ & $(-6.01)$ \\
\hline
\end{tabular}


content of the trading behaviour of investors is directly related to the size of trades. On the other hand, from an empirical point of view, it has been amply documented that there exists a positive relation between volume and volatility. ${ }^{17}$

In a very important paper, however, Jones et al. (1994) show that on average the size of trades has virtually no incremental information content once the number of transactions is taken into account. In other words, the well accepted positive relation between volume and volatility becomes insignificantly different from zero when volatility is conditioned on the number of transactions.

This finding may explain the strong relation that we found between spreads and the number of transactions within a time-series framework. The information content in trading behaviour is captured through the number of transactions that take place during a particular interval of time.

Given the important differences in the trading mechanism between a continuous dealer market and our continuous auction market, it was decided to analyse the relation between volatility and the number of transactions.

In order to estimate the conditional standard deviations of daily returns, the procedure suggested by Schwert (1990), and employed by Jones et al. (1994), is followed. It is an extremely easy way to estimate conditional volatilities and, at the same time, the procedure allows for stylised facts concerning stock return volatility.

We first estimate the unexpected return on day $t$ for all stocks in the sample with continuous data from 2 January 1991 to 18 October 1994. Thus, a total of 60 securities are available for the exercise. The unexpected returns of these stocks are given by the residuals of the following regression model:

$$
R_{i t}=\sum_{j=1}^{5} \hat{\alpha}_{i j} D_{j t}+\sum_{t=1}^{12} \hat{\beta}_{\tau} R_{i t-\tau}+\hat{\varepsilon}_{i t}
$$

Given that the expectation of the absolute value of a normal random variable equals $(2 / \pi)^{1 / 2}$ times its standard deviation, the absolute residuals of equation (5) are multiplied by $(2 / \pi)^{-1 / 2}$ to get the volatility of unexpected returns. ${ }^{18}$ In the regression above, five day-of-the-week dummies are included to capture differences in mean returns. Moreover, stock returns are regressed on 12 lagged returns to estimate short-term movements in conditional expected returns.

These estimates of conditional volatility are regressed on the number of transactions and the average trade size (total number of shares divided by the number of transactions) to determine the relative importance of both variables. This exercise is performed by dividing the total number of stocks into five size-sorted portfolios, where ranking is obtained according to the market value of all 60 securities at the end of 1992. This date corresponds to the midpoint of our sampling period. In particular, for individual stocks within each of the five sizesorted portfolios, we run seemingly unrelated regressions of our estimates of daily conditional volatility of returns on a trading-gap dummy variable, average trade size, number of transactions, and 12 lagged absolute residuals from equation (5) to correct any persistence of volatility: $:^{19}$

$$
\left|\hat{\varepsilon}_{i t}\right|=\alpha_{i}+\beta_{i m} D_{M t}+\beta_{i v} \sqrt{A V_{i t}}+\beta_{i n} \sqrt{N_{i t}}+\sum_{i=1}^{12} \rho_{i \mathrm{r}}\left|\hat{\varepsilon}_{i t-\mathrm{r}}\right|+\omega_{i t}
$$


where $D_{M t}$ equals 1 for Mondays and 0 otherwise, $A V_{i t}$ is the average trade size of stock $i$ within a portfolio $p, N_{i t}$ represents the number of transactions of stock $i$ in portfolio $p$, and $\rho_{i \text { r }}$ measures the persistence of volatility in stock $i$.

The results are contained in Table 6 . It seems that volatility is primarily determined by the number of transactions. In all portfolios, there exists a strong positive relation between transactions and volatility. The information content of trading behaviour is basically contained in the number of transactions during the day. It is also the case that there is a positive relation between volatility and average trade size for the smallest firms. However, it seems evident that the economic significance of this relation is negligible relative to the importance of the number of transactions. It should also be noted that the relation between average trade size and volatility becomes negative for large firms. Nevertheless, the economic relevance of this relation seems to be rather small. At the same time, there is (almost) a decreasing monotonic relation between the relative impact of transactions on volatility and firm size with the effect largest for the smallest firms. This suggests that the information content of trading incorporated into the number of transactions is particularly relevant for small firms. It may be the case that the relatively little information about small firms may be the reason behind these results. Finally, it is interesting to point out the decreasing monotonic relation between the magnitude of the coefficients associated to the Monday dummy variable and firm size.

Table 6

The relation between volume, number of transactions and volatility.

Estimates of seemingly unrelated regressions of daily percentage volatility of returns on a daily trading-gap dummy variable, average trade size, number of daily transactions and 12 lagged absolute residuals:

$$
\left|\hat{\varepsilon}_{i t}\right|=\alpha_{i}+\beta_{i m} D_{M t}+\beta_{i n} \sqrt{A V_{n}}+\beta_{i n} \sqrt{N_{i t}}+\sum_{i=1}^{12} \rho_{i t}\left|\hat{\varepsilon}_{t-1}\right|+\omega_{n}
$$

where $\left|\hat{\varepsilon}_{i t}\right|$ is the absolute value of the return of stock $i$ in day $t$ conditional on its own 12 lags and day-of-the-week dummies. These values are multiplied by $(2 / \pi)^{-1 / 2} \cdot D_{M t}$ equals 1 for Mondays and 0 otherwise, $A V_{u t}$ is the average trade size, and $N_{i t}$ is the number of transactions for stock $i$ on day $t$. The stocks in the sample have unbroken series of daily closing transaction prices from January 1991 to October 1994. These stocks are classified into five portfolios according to their market value at the end of 1992. Seemingly unrelated regressions are run for individual stocks within each sizesorted portfolio. Each portfolio contains 12 stocks. $t$-statistics in parentheses.

\begin{tabular}{lccc}
\hline Portfolios & $\beta_{i m}$ & $\beta_{i+}$ & $\beta_{i n}$ \\
\hline MVAL1 & 0.4540 & 0.0045 & 0.2285 \\
& $(5.06)$ & $(2.10)$ & $(25.96)$ \\
MVAL2 & 0.3210 & -0.0009 & 0.1254 \\
& $(4.66)$ & $(-0.49)$ & $(22.81)$ \\
MVAL3 & 0.1872 & -0.0056 & 0.1505 \\
& $(2.80)$ & $(-3.04)$ & $(22.14)$ \\
MVAL4 & 0.1552 & $(-0.0090$ & 0.0861 \\
& $(1.55)$ & -0.0066 & $(15.17)$ \\
MVAL5 & 0.0245 & $(-5.86)$ & 0.0769 \\
& $(0.49)$ & & $(22.84)$ \\
\hline
\end{tabular}


All this evidence may indicate that the effects of dividend announcements on spread may change if we control for the apparently large information content of trading contained in the number of transactions. This issue is analysed in the next section of the paper.

\section{Dividend announcements and bid-ask spreads: multivariate empirical evidence}

Given an empirical evidence found in Sections 5 and 6, it becomes necessary to study whether the apparent reduction in information asymmetry risks of Tables 3 and 4 documents either a changing compensation of adverse selection during dividends announcements or simply reflects the general relation between spreads and transactions.

This issue is particularly relevant for the literature dealing with the sensitivity of liquidity providers to the arrival of new information which may alter asymmetries of information among agents. It should be noted that the paper by Lee et al. (1993) controls for volume when analysing the impact of earnings announcements on market liquidity. However, they ignore the potential effects of the number of transactions, which may be really behind their significant results. Our plan for this section is to study the impact of dividend announcements on spread controlling for both volume and transactions in two separate multiple regression tests. This would allow us to reach precise conclusions about changing compensation of adverse selection.

In order to carry out these tests, a time-series regression is run for each stock in the sample that had at least one dividend announcement with the percentage seasonally adjusted spread as the dependent variable, and event period dummy variables, and either volume or transactions as the independent variables. In particular the following regression with daily data from 2 January 1991 to 18 October 1994 is performed for each stock:

$$
\text { Spread }_{t}=\alpha+\beta_{c t} C V_{t}+\sum_{\tau=-4}^{+4} \delta_{\tau} D_{t}+v_{t}
$$

where, as in equation (3), the spread variable is given by:

$$
\left(\frac{S P_{\iota}}{S \bar{P}_{(t)}}-1\right) \times 100
$$

and the control variable, $C V_{t}$, is either the normalised volume or the normalised transactions of equation (3):

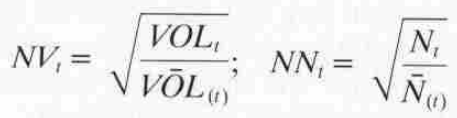

To capture spread shifts around dividend announcements a dummy variable, $D_{t}$, is included which equals 1 if observation $t$ is event day $\tau$ and 0 otherwise. The coefficients associated with these indicator variables represent changes in the mean of the spread during the event period, after controlling for the poten- 
tial effects of either volume or transactions. Finally, the error term of equation (7) is assumed to be, $v_{t}=u_{t}+\gamma v_{t-1}$, where $\gamma$ is the AR(1) parameters, and $u_{t}$ is an independent and identically distributed normal variable with mean zero and constant variance.

The results are contained in Table 7 . The reported coefficients are the crosssectional average of the estimated coefficients obtained with the individual regressions given by the expression (7). As before, in parentheses we present the $t$-statistics under the null hypothesis that the cross-sectional mean of the coefficients equals zero. White consistent standard errors are used. This table shows the results for the complete sample of 157 dividends announcements.

The conclusions that may be drawn from Table 7 are clear. Controlling for the number of transactions does affect the results about the impact of dividends announcements on the spread a day before the announcement, as well as during the announcement period. ${ }^{20}$ The significant $12 \%$ reduction in spread that we reported in Table 3 for the day of the announcement decreases to an insignificant $4 \%$ once we control for the number of transactions. It is interesting to note that the decrease also becomes insignificant when we control for volume. In this case, however, the magnitude of the reduction remains around $6 \%$ (with a $t$ statistic of 1.57). Very similar results are found for the day before the announcement. In general, controlling for the number of transactions has larger effects on the mean shifts of the spread over the whole event window than controlling for volume. This is of course the result we expected, given the evidence contained in Tables 5 and 6 .

There is another sense in which controlling for the number of transactions in this type of study may be the appropriate way to perform the analysis. Moreover, this may be a particularly relevant issue for continuous auction markets. In a recent working paper, Kumar and Seppi (1993) show that when limit orders and market orders are allowed to co-exist, the structure of the limit book may present a widening spread between the best buy and sell orders exclusively due to anticipated increases in stock return volatility around dividend announcements. The point which they emphasise is that this may even be the case without adverse selection. In our case, the impact is not significant so that the potential disturbing effects of anticipated volatility does not seem to be relevant. In general, however, the results of Table 6 suggest that controlling for the number of transactions would tend to avoid confounding effects between adverse selection and anticipated volatility. This implies that by including the number of transactions in our regressions we may be in fact eliminating these effects. ${ }^{21}$

The empirical evidence in Table 7 completely reverses the partial conclusions we drew from Table 3. Liquidity providers do not seem to be sensitive to changing information risks around dividend announcements. Hence, the bid-ask spread does not seem to contain any compensation for adverse selection. In the continuous Spanish Stock Exchange auction trading mechanism, we do not find any evidence after controlling for the number of transactions that information asymmetry decreases during dividend announcements. It may be argued, of course, that an alternative but coherent explanation of our results may simply be that dividend announcements are not an adequate proxy for information asymmetries among market participants. It may be also possible that both spread and transactions (or volume) are endogenously determined. If this is the case, the results may suggest that our way of controlling for the number of transactions 
Table 7

Changes in spread around dividend announcements controlling for either volume or number of transactions.

For each stock in the sample that had at least one dividend announcement, a time-series regression is run with spread as the dependent variable and event period dummy variables, and either volume or the number of transactions as the independent variables. In particular the following regression with daily data from January 1991 to October 1994 is performed for each stock:

where the spread variable is given by:

$$
\begin{aligned}
& \text { Spread }_{t}=\alpha+\beta_{c t} C V_{t}+\sum_{t=-4}^{+4} \delta_{t} D_{t r}+v_{t} \\
& \text { is given by: }
\end{aligned}
$$

$$
\left(\frac{S P_{t}}{S \bar{P}_{(t)}}-1\right) \times 100
$$

where $S P_{t}$ is the actual spread during day $t$, and $S \bar{P}_{(i)}$ is the average of the spread for the corresponding day of the week. The control variable, $C V_{t}$, is either normalised volume $(N V)$ and normalised transactions $(N N)$, and are given by:

$$
N V_{t}=\sqrt{\frac{V O L_{t}}{V \bar{O} L_{(t)}}} ; \quad N N_{t}=\sqrt{\frac{N_{t}}{\bar{N}_{t(t)}}}
$$

$D_{t r}$ equals 1 if observation $t$ is event day $\tau$ and 0 otherwise. The error term is given by: $v_{t}=u_{t}+\gamma v_{t-1}$, where $\gamma$ is the $\operatorname{AR}(1)$ parameter and $u_{t}$ is iid normal with mean zero and constant variance. The reported coefficients are the cross-sectional average across all coefficients. In parentheses we report the $t$-statistics under the null hypothesis that the cross-sectional mean of the coefficients equals zero. White standard errors are used. Results for the complete sample of dividend announcements are reported.

\begin{tabular}{lrr}
\hline Coeffs & Regressions with transactions & Regressions with volume \\
\hline$\beta_{c r}$ & -80.87 & -42.88 \\
$\delta(-4)$ & $(-17.72)$ & $(-16.10)$ \\
& -0.422 & -1.628 \\
$\delta(-3)$ & $(-0.08)$ & $(-0.31)$ \\
$\delta(-2)$ & -0.505 & -0.632 \\
& $(-0.05)$ & $(-0.06)$ \\
$\delta(-1)$ & -4.740 & -0.726 \\
$\delta(0)$ & $(-0.80)$ & $(-0.12)$ \\
$\delta(+1)$ & -3.221 & -6.874 \\
$\delta(+2)$ & $(-0.68)$ & $(-1.57)$ \\
$\delta(+3)$ & -4.159 & -6.144 \\
& $(-0.91)$ & 6.115 \\
$\delta(+4)$ & 7.472 & $(0.91)$ \\
& $(1.14)$ & -5.442 \\
& -3.947 & -2.501 \\
& $(-0.82)$ & $(-0.43)$ \\
& -1.339 & 9.207 \\
\end{tabular}


and volume goes too far. This is a very controversial issue. Unfortunately, we do not know the proper way of dealing with this potential problem.

Panels A and B of Table 8 contain similar empirical evidence. In these two panels, the results are partitioned by the increased, maintained, or decreased dividends relative to the previous payment at (approximately) the same time the year before the announcement. For the first two groups we do not find any significant change in the bid-ask spread during the event window from day -4 to day +4 . It should be recalled that before we controlled for the number of transactions the reduction of spread on the day before the announcement, as well as during the event day, was larger for companies announcing a decrease in their dividend payments. In other words, a negative signal seemed to convey a very strong reduction in information asymmetry risks. This was a rather surprising result. In fact, we may now conclude that the negative relation between the number of transactions and spreads explains the significant change in information asymmetry risks found in Table 3. We observe from Panel A of Table 8 that the former reductions of spread even become positive after we control for the number of transactions. It should be recognised that our three groups of dividend changes exhibit some evidence of differential effects during the day before the announcement. Increased dividend firms have a $10 \%$ reduction in spread ( $t$-statistics of 1.22), maintained dividend stocks more than $4 \%$ fall in spread, whilst decreased dividend companies present a positive change of $15 \%$ $(t$-statistics of 1.23). In any case, neither of these percentage changes is significantly different from zero.

Panel B of Table 8 shows that the same result holds true when we control for the number of shares traded.

In general, we may suggest that the arrival of negative news about the future prospects of a firm does not seem to incorporate changes in information asymmetry risk beyond what is normally conveyed through increased number of transactions. It should be pointed out, however, that there is an exception. The impact on spread remains negative and significant four days before the announcement, even after we control for the number of transactions. If traders anticipate the announcement date for potentially distressed companies, there may be an increase in their liquidity that may be reflected somehow in the reduction of spread. It should be pointed out that this group of announcements exhibits high and positive percentage changes in the number of transactions from day -4 to day +2 . This suggests that information arrives to the market four days before the announcement. We also find some negative percentage changes in the spread of these companies during the days before and up to the event window employed in Table 8 . As before, it may be an indication that the timing throughout the year of dividend announcements is predictable. However, negative percentage changes cannot be attributed to adverse selection. During these pre-announcement days, spread should become wider if adverse selection is behind the observed changes of spread.

Finally, if relatively little information about small firms reaches the market during periods other than dividend announcements, we might expect dividend change announcements to convey more information for small firms than for large firms. In order to analyse this possibility, we divide our sample in two groups according to the size of companies at the end of the year preceding the announcement. There are 36 dividend announcements of small firms, and 121 


\section{Table 8}

Changes in spread around dividend announcements controlling for either volume or number of transactions. Announcements are classified according to the change in the dividend payment.

For each stock in the sample that had at least one dividend announcement, a time-series regression is run with spread as the dependent variable and event period dummy variables, and either volume or the number of transactions as the independent variables. In particular the following regression with daily data from January 1991 to October 1994 is performed for each stock:

where the spread variable is given by:

$$
\text { Spread }_{t}=\alpha+\beta_{t r} C V_{t}+\sum_{r=-4}^{+4} \delta_{t} D_{t r}+v_{t}
$$

$$
\left(\frac{S P_{t}}{S \bar{P}_{(t)}}-1\right) \times 100
$$

where $S P_{t}$ is the actual spread during day $t$, and $S \bar{P}_{(t)}$ is the average of the spread for the corresponding day of the week. The control variable, $C V_{t}$, is either normalised volume $(N V)$ and normalised transactions $(N N)$, and are given by:

$$
N V_{t}=\sqrt{\frac{V O L_{t}}{V \bar{O} L_{(\ell)}}} ; \quad N N_{t}=\sqrt{\frac{N_{t}}{\bar{N}_{(t)}}}
$$

$D_{t i}$ equals 1 if observation $t$ is event day $\tau$ and 0 otherwise. The error term is given by: $v_{t}=u_{t}+\gamma v_{t-1}$, where $\gamma$ is the $\operatorname{AR}(1)$ parameter and $u_{t}$ is iid normal with mean zero and constant variance. The reported coefficients are the cross-sectional average across all coefficients. In parentheses we report the $t$-statistics under the null hypothesis that the cross-sectional mean of the coefficients equals zero. White standard errors are used.

\begin{tabular}{lrrr}
\hline Coeffs & \multicolumn{3}{c}{ Panel A: Regressions with transactions } \\
& Increased dividends & Maintained dividends & Decreased dividends \\
\hline$\beta_{c \text { cr }}$ & -88.097 & -72.186 & -90.984 \\
$\delta(-4)$ & $(-10.26)$ & $(-11.62)$ & $(-9.96)$ \\
& -1.893 & 7.126 & -19.372 \\
$\delta(-3)$ & $(-0.24)$ & $(0.85)$ & $(-2.58)$ \\
& 15.318 & -7.405 & -13.805 \\
$\delta(-2)$ & $(0.59)$ & $(-1.00)$ & $(-1.53)$ \\
& -8.539 & -2.438 & -3.431 \\
$\delta(-1)$ & $(-0.88)$ & $(-0.26)$ & $(-0.33)$ \\
& -10.147 & -4.691 & 15.730 \\
$\delta(0)$ & $(-1.22)$ & $(-0.77)$ & $(1.23)$ \\
& -6.089 & -7.109 & $(0.646)$ \\
$\delta(+1)$ & $(-0.85)$ & $(-1.17)$ & 13.487 \\
& -7.138 & 15.987 & $(0.97)$ \\
$\delta(+2)$ & $(-1.02)$ & $(1.39)$ & -2.177 \\
& -3.721 & -4.715 & $(-0.20)$ \\
$\delta(+3)$ & $(-0.44)$ & $(-0.68)$ & 2.567 \\
$\delta(+4)$ & -1.090 & -2.856 & $(0.20)$ \\
& $(-0.13)$ & $(-0.31)$ & $(0.972$ \\
& 32.599 & 0.521 & $(0.05)$ \\
\hline
\end{tabular}


Table 8 - continued

\begin{tabular}{lrrr}
\hline Coeffs & \multicolumn{3}{c}{ Panel B: Regressions with volume } \\
& Increased dividends & Maintained dividends & Decreased dividends \\
\hline$\beta_{c r}$ & -43.359 & -39.372 & -52.149 \\
$\delta(-4)$ & $(-10.67)$ & $(-10.10)$ & $(-7.35)$ \\
& -3.036 & 8.044 & -26.920 \\
$\delta(-3)$ & $(-0.40)$ & $(0.89)$ & $(-4.05)$ \\
& 17.596 & -7.075 & -20.356 \\
$\delta(-2)$ & $(0.65)$ & $(-0.93)$ & $(-2.43)$ \\
& -6.329 & $(0.41)$ & -2.270 \\
$\delta(-1)$ & $(-0.64)$ & -6.441 & $(-0.20)$ \\
& -11.092 & $(-1.07)$ & $(0.0783$ \\
$\delta(0)$ & $(-1.42)$ & -7.689 & 0.535 \\
& -7.166 & $(-1.33)$ & $(0.05)$ \\
$\delta(+1)$ & $(-0.81)$ & 15.288 & $(0.40)$ \\
$\delta(+2)$ & -6.597 & $(1.30)$ & $(-10.442$ \\
& $(-0.96)$ & -7.532 & -0.364 \\
$\delta(+3)$ & -0.192 & $(-1.14)$ & $(-0.03)$ \\
$\delta(+4)$ & $(-0.02)$ & -5.800 & -2.989 \\
& 1.046 & $(-0.62)$ & $(-0.24)$ \\
\hline
\end{tabular}

announcements of large firms. It should be clear that the ranking of these companies is established using all the stocks in our sample, and not only companies with dividend announcements. This implies that either small or large is defined similarly to the portfolios used in the first part of this paper.

The empirical results, not shown in this paper, do not reveal any significant change in spread during the event window. It is interesting to note, however, that the decrease in spread is found to be larger for the companies with the largest market value.

A final word of caution. Given data availability, it is not possible to employ a measure of the effective (implicit) bid-ask spread. Lee et al. (1993), and Petersen and Fialkowski (1994) argue that effective spread rather than quoted spread is the relevant measure of transaction costs faced by investors. Effective spread measures the average spread paid on the shares transacted during a given period. In this sense, our data seems to be a reasonable approximation. However, effective spread is volume-weighted. Further research as well as more precise data may help to clarify these unsolved issues.

\section{Summary and conclusions}

This paper has analysed liquidity changes in response to dividend announcements for a representative sample of stocks traded in the continuous Spanish Stock Exchange auction system. The previous empirical evidence is limited to continuous dealer markets where both the spread and depth are established by market makers. It is also the case that previous research has concentrated 
on the impact of earnings announcements. We argue that similar adverse selection compensation might be part of the implicit bid-ask spreads in continuous auction trading mechanisms. Moreover, previous statistical designs have controlled for contemporaneous volume. Our results indicate that number of transactions is the appropriate controlling variable when analysing changes in information asymmetry risks around either dividends or earnings announcements.

Interestingly liquidity and trading regularities have been found in the continuous Spanish market. However, dividend announcements do not seem to convey significant changes in information asymmetry risks. Neither spread nor our measure of depth change significantly during the day of the announcement or during the post-announcement period after we control for the reaction in the number of transactions. Hence, adverse selection does not seem to be part of the implicit bid-ask spread, at least when we limit our attention to dividend announcements.

Contrary to the evidence reported for earnings announcements in the US dealer market, we do not observe any indication that liquidity providers are sensitive to changes in information asymmetry risks. To discover whether these results are due to the idiosyncratic characteristic of the announcement or, alternatively, they reflect important differences in trading mechanisms, requires further research.

\section{Notes}

We are grateful to Roberto Blanco from the Spanish Security Exchange Commission and Jorge Yzaguirre from the Spanish Stock Exchange for providing the data necessary to perform this study. Versions of this paper were presented at the Fundación BBV II Jornadas de Economía Financiera (Bilbao, June 1995), the European Financial Management Association, 4th Annual Meeting (London, June 1995), the III Foro de Finanzas (Bilbao, November 1995) and the conference on European Financial Markets: Microstructure and Regulation (London, January 1996). We are grateful for helpful comments from participants and, in particular, from Ignacio Peña, Rafael Salinas, Kaj Hedvall, Louis Chan, and Yakov Amihud. We would also like to acknowledge the financial support provided by the Dirección General Interministerial Científica y Técnica (DGICYT), project no. PB94-1373. The contents of this paper are the sole responsibility of the authors.

1. The Toronto Stock Exchange first adopted this system in 1977. The Tokyo Stock Exchange and the Paris Bourse are also examples of this type of trading mechanism. Hamao and Hasbrouck (1995) and Biais et al. (1994) present a detailed description of the dynamics of trades and quotes for both markets. They also discuss the general institutional characteristics of these markets. On the other hand, Glosten (1994) provides an analysis of the nature of equilibrium of an idealised electronic open limit order book and how it competes against other methods of exchanging securities.

2. See Lee et al. (1993) for a detailed analysis.

3. Of course, spread is understood as the difference between the best ask and the best bid available at any particular point in time. The exact measure of the spread employed in the analysis will be described later.

4. This sample represents more than $90 \%$ of total market capitalisation at any time during the sampling period.

5. All stocks included in the second data set belong to the first data set. We have a total of 959 trading days. 
6. See Rubio (1988) for details.

7. Due to tax-induced trading, turnover of small firms is much larger during December and January. [See Basarrate and Rubio (1994)].

8. See also the work by Brennan and Subrahmanyam (1994). They employ an alternative measure of depth to study the compensation of adverse selection in stock returns.

9. We employ the term relative spread or percentage spread indistinctly throughout the paper.

10. See Miller and Rock (1985).

11. For the US market see, among others, Asquith and Mullins (1983), Bajaj and Vijh (1990), and John and Lang (1991). Recently, González (1995) has reported evidence consistent with significant information content of dividend changes in the Spanish Stock Exchange.

12. White-consistent standard errors are employed. It should be recalled that in the case of the spread, $\mathrm{S}_{t}$ is the absolute value of the spread. Of course, $S_{t}$ is divided by the average of the spread for the corresponding day of the week. This implies that our measure is not biased by price effects. Our statistic is consistent with a measure defined in terms of the relative spread.

13. See McInish and Wood (1992) for a recent summary of literature, and new evidence with intraday data.

14. This argument assumes a negative relation between depth and spreads.

15. The same positive relation is found between volume and spreads.

16. See Kyle (1985), and Admati and Pfleiderer (1988).

17. See Gallant et al. (1992).

18. This estimator is unbiased if the conditional distribution of returns is normal.

19. Each regression is performed with 12 stocks and 959 daily observations. The average correlation between the average trade size and the number of transactions across all securities in the sample is 0.09 .

20. In principle, confounding effects between transactions and changing information risks may be relevant only during the announcement and post-announcement periods. Note, however, that dividend announcements seem to convey information as from, at least, the day before the announcement.

21. Note, of course, that volume represents the total number of shares traded. This includes both the number of transactions and the average trade size. In this sense, volume might be sufficient as a control variable. However, the average trade size is found to be irrelevant in controlling the impact of dividend announcements on spread.

\section{References}

Admati, A. and Pfleiderer, P., 'A theory of intraday patterns: Volume and price variability', The Review of Financial Studies, Vol. 1, 1988, pp. 3-40.

Asquith, P. and Mullins, D., 'The impact of initiating dividend payments on shareholders' wealth', Journal of Business, Vol. 56, 1983, pp. 77-95.

Bajaj, M. and Vijh, A., 'Dividend clienteles and the information content of dividend changes', Joumal of Financial Economics, Vol. 26, 1990, pp. 193-219.

Barclay, M. and Dunbar, C., 'Private information and market depth', Working Paper, University of Rochester.

Basarrate, B. and Rubio, G., 'La imposición sobre plusvalías y minusvalías y el volumen de contratación en el mercado bursátil', Moneda y Crédito, Vol. 199, 1994, pp. 97-123.

Biais, B., Hillion, P. and Spatt, C., 'An empirical analysis of the limit order book and the order flow in the Paris Bourse', Journal of Finance, forthcoming.

Brennan, M. and Subrahmanyam, A., 'Market microstructure and asset pricing: On the 
compensation for adverse selection in stock returns', Working Paper, University of California, Los Angeles, 1994.

Daley, L., Hughes, J. and Rayburn, J., 'The impact of earnings announcements on the adverse selection problem of market makers', Working Paper, University of Minnesota, 1991.

Easley, D. and O'Hara, M., 'Time and the process of security price adjustment', Journal of Finance, Vol. 47, 1992, pp. 577-605.

Gallant, R., Rossi, P. and Tauchen, G., 'Stock prices and volume', The Review of Financial Studies, Vol. 5, 1992, pp. 199-242.

Glosten, L., 'Is the electronic open limit order book inevitable?, Journal of Finance, Vol. 49, 1994, pp. 1127-1161.

González, F., 'La reacción de los precios de las acciones ante anuncios de dividendos: La evidencia empírica en el mercado Español de valores', Investigaciones Económicas, Vol. 19,1995 , pp. $249-268$.

Hamao, Y. and Hasbrouck, J., 'Securities trading in the absence of dealers: Trades and quotes on the Tokyo Stock Exchange', Review of Financial Studies, Vol. 8, 1995, pp. 849-878.

Harris, M. and Raviv, A., 'Differences of opinion make a horse race', The Review of Financial Studies, Vol. 6, 1993, pp. 473-506.

John, K. and Lang, L., 'Insider trading around dividend announcements: Theory and evidence', Journal of Finance, Vol. 46, 1991, pp. 1361-1389.

Jones, C., Kaul, G. and Lipson, M., 'Transactions, volume and volatility', The Review of Financial Studies, Vol. 7, 1994, pp. 631-651.

Kim, O. and Verrecchia, R., 'Market liquidity and volume around earnings announcements', Journal of Accounting and Economics, Vol. 17, 1994, pp. 41-67.

Kumar, P. and Seppi, D., 'Limit and market orders with optimizing traders', Working Paper, Carnegie Mellon University, 1993.

Kyle, A., 'Continuous auctions and insider trading', Econometrica, Vol. 53, 1985, pp. 1315-1336.

Lee, C., Mucklow, B. and Ready, M., 'Spreads, depths, and the impact of earnings information: An intraday analysis', The Review of Financial Studies, Vol. 6, 1993, pp. $345-374$.

Lehmann, B. and Modest, D., 'Trading and liquidity on the Tokyo Stock Exchange: A bird's eye view', Journal of Finance, Vol. 49, 1994, pp. 951-984.

McInish, T. and Wood, R., 'An analysis of intraday patterns in bid-ask spreads for NYSE stocks', Journal of Finance, Vol. 47, 1992, pp. 753-764.

Miller, M. and Rock, K., 'Dividend policy under asymmetric information', Joumal of Finance, Vol. 40, 1985, pp. 1031-1051.

Morse, D. and Ushman, N., 'The effect of information announcements on the market microstructure', Accounting Review, Vol. 59, 1983, pp. 247-258.

Petersen, M. and Fialkowski, D., 'Posted versus effective spreads: Good prices or bad quotes?', Journal of Financial Economics, Vol. 35, 1994, pp. 269-292.

Rubio, G., 'Further international evidence on asset pricing: The case of the Spanish capital market', Journal of Banking and Finance, Vol. 12, 1988, pp. 221-242.

Schwert, W., 'Stock volatility and the crash of '87', The Review of Financial Studies, Vol. 3, 1990, pp. 77-102.

Skinner, D., 'Stock returns, trading volume, and bid-ask spreads around earnings announcements: Evidence from the NASDAQ national market system', Working Paper, University of Michigan, 1991.

Venkatesh, P. and Chiang, R., 'Information asymmetry and the dealer's bid-ask spread: A case study of earnings and dividend announcements', Joumal of Finance, Vol. 5, 1986, pp. 1089-1102. 